\title{
A Case Study of a Chinese Postgraduate Student's Perceptions of Studying in a New Zealand University*
}

\author{
Sijia Xue \\ The International College, Xiamen University, \\ 361102, China \\ Email: xuesijia@126.com
}

\author{
Dave Yan \\ Aspiring Language Institute, Auckland, 1010, \\ New Zealand \\ Email: dave.yan.nz@gmail.com
}

\begin{abstract}
This article reports on a case study which investigated a teacher student's perceptions of his international experience in the academic study at a New Zealand university. The study formulated two research questions and conducted an in-depth interview with this ESL learner. The learner's journal to reflect his expectations and experiences was also provided and used to further analyse and consolidate the data gained from the interview. This article carried out a qualitative analysis of the data in order to answer two research questions. The learner's articulations revealed that his expectations and experiences interrelated in complex, sometimes unexpected, ways. The results of the study bring important implications for Chinese ESL students to adapt to their life in the Western university as soon as possible. It also leads to the idea that some smoother communications among peers and/or between the learner and the academic advisor are needed to ensure students' academic success.
\end{abstract}

Keywords - Chinese ESL Learner; Academic Study; Perceptions

\section{INTRODUCTION}

New Zealand has been recognised as one of the top five countries receiving international students in terms of trade amount[3]The yearly enrolment of international students in New Zealand has hovered around the 100,000 since 2003. This is a significant figure compared to 1999 when the population of international students was less than 30,000 . Meanwhile, China becomes New Zealand's single largest source of international students. The majority of Chinese students study in Auckland, with Canterbury the second most popular destination[7].

The language and culture differences as well as Western teaching styles pose barriers that eventually lead a lot of Chinese students to indulge in a Chinese circle cut off from the outside. It seems that these young men, who flock out of their country to seek higher education, have never reached the other side of the south-west Pacific Ocean. Not surprisingly, some frustrations and struggles even exist in the students, who enrolled in the postgraduate programme in

\footnotetext{
* The research is sponsored by the Educational Scientific Research Foundation for Middle-aged and Young Teachers of Fujian Province, China (Project No.: JAS150071)
}

language teaching, which is becoming popular, especially for non-native English teachers, in an English-speaking country. The teacher students aim to get an opportunity to improve their language proficiency, to develop their pedagogical knowledge and to receive a qualification from an institution of higher learning, which immediately places that teacher as a "professional" teacher.

This study sought to investigate a postgraduate ESL teacher-student's expectations and experiences during the postgraduate programme in an attempt to provide a detailed picture of what he faced and how he felt and tried to be successful in the academic study. In other words, the aim of this article is to record how the ESL learner's expectations and experiences alter each other, and how the perceptions of his learning experience are intertwined with his realistic expectation.

\section{LITERATURE REVIEW}

A greater awareness of international students' problems and a commitment to meeting their needs are critical for academic institutions to win the competition for overseas students market, which brings into focus variables not readily identified by existing understandings of learners' needs[18]. For some time, the literature has been highlighting the need for university staff to look carefully to the background experiences of students from other cultures. Without doubt, institutions of higher learning have a vital part to play to transmit their respective national culture, and to promote appreciation of cultural diversity to the students knocking on their doors.

Research into the nature and extent of problems faced by overseas students in the Western university is based almost entirely on surveys of the overseas student population, mainly from the perspective of support service staff. These reports give detailed descriptions of the overseas student population in a particular tertiary institution and are concerned with: English language proficiency, coping with the educational system and its demands, cultural adjustment to life in a foreign country, and provision of support services and their usefulness to overseas students. However, the exact nature of these "language" or "study" problems is still relatively unknown. 
Dewey[8]had been challenging educators to take account of individual differences by looking to the experiential learning of the students and the specific context of their experience. Burns [6] pointed out that, newly-arrived students have considerably higher stress levels amongst overseas students when compared with local students. Dunkin[9]has explored the qualities of expert versus novice teachers in higher education. The expert qualities that enable teachers to facilitate students' learning include many of the points made in the reported studies related to international students' needs as learners. Mayhew et al.[14] also alert us to the need for greater understanding on programmes that will assist international students' transition. Some researchers argue that adaptation is an umbrella term that encompasses other similar but narrower terms, such as culture shock, assimilation, adjustment and acculturation.[13] Both adaptation and adjustment are usually used to describe individuals while acculturation and assimilation tend to refer to groups rather than individuals by some researchers.

There is a number of publications exploring the differences between Asian and Western educational systems, their respective philosophies of education, conceptions of knowledge, standards and expectations posed by different systems, and learning approaches needed to attain the goals and aims of a given educational system. The outcome of a student's learning depends on the approach taken, which in turn is influenced by the learner's perception and interpretation of the learning context (teaching, assessment, curriculum, nature of learning tasks), based to a large extent on previous learning experiences and on his/er conception of learning.

The term "perception" can refer to the "structure of assumptions within which one's past experience assimilates and transforms new experience",[15] which encompasses a habitual set of expectations providing an orienting frame of reference that one uses in the interpretation of experience. At the same time, the perception serves as serves as a tacit belief system for the interpretation and evaluation of the experience.

Expectations are shaped by student's perceptions of the reasons for successes and failures.[22] Students attribute successes and failures to either changeable or unchangeable factors (for example, effort and ability, respectively), influenced by beliefs and expectations that they pick up from, among others, their own experience. However, the interplay of expectations with changeable and unchangeable attribution factors is moderately complex when looked at in detail.

Expectations are double-edged swords, raising or lowering learner's outcomes according to the positive or negative nature of the expectations. Schilling and Schilling [20] capture well the broad idea that expectations are vital to education: "the literature suggests that expectations shape the learning experience very powerfully." For example, classic studies in the psychology literature have found that merely stating an expectation results in enhanced performance, that higher expectations result in higher performance, and that persons with high expectations perform at a higher level than those with low expectations, even though their measured abilities are equal.

Expectations, which are developed prior to experience with a particular process, context or role, are also shaped by beliefs, that is, "mental constructions of experience"[23] that are held to be true and that guide behaviour. Such expectations may influence how individuals react, respond and experience a new environment. Learner's beliefs help individuals to define and understand the world and themselves, and as such have an adaptive function[17]; beliefs are instrumental in defining tasks and play a critical role in defining behaviour.[21]The belief systems learners hold or develop and reflective experience help them to adapt to new environments, to define what is expected of them and to act in accordance with those understandings.

\section{Methodology}

The research aimed to explore the expectations and experiences of a postgraduate ESL student, more specifically, the perceptions of the student in his academic study. The research questions, which were utilized from the ones in the Barkhuizen and Feryok's [2] study, were asked as below:

(1) How does his expectation structure his experience?

(2) How does his experience alter his expectation?

\section{A. The Participant}

The research reports on a case study which investigated a postgraduate ESL student's perceptions of his 12 months' learning experience in Auckland, New Zealand. He is a young (26) Chinese who come to Auckland, New Zealand in October 2009 with a Working Holiday Visa. A graduate majoring in English from a Chinese university, he had been a teacher of English working in a Sino-Canadian school. After 2 months in Auckland, he achieved an IELTS band of 7 and applied for a postgraduate programme in language teaching, then enrolled 4 courses in the first semester. He started his study at University of Auckland in March 2010.

\section{B. Data Collection}

Although there are different approaches to analysing qualitative data, they all follow a similar sequence.[10] The sequence could be simplified: coding for themes - looking for patterns - making interpretations - building theory. In order to obtain answers to the research questions, the following data-collection procedures were employed:

- An in-depth interview with the ESL student was conducted. During the interview, we used open-ended, rather than standardized forms of questioning. Although there were general questions used to guide the interview, much of the time we spent with the participant became more like informal dyadic conversations, enabling the participant to engage in the process of dialogical authoring. The participant was willing to articulate for himself and expresses his ideas, feelings, concerns, changing expectations and experiences of his time in Auckland. As Freeman[2]says, "One needs the words to talk about what one does, and in using words one can see it more clearly". Audio recording method was used in sampling naturally occurring utterances. The interview was then transcribed.

- A reflective journal in which the student wrote about his expectation and goals of his study, his initial and later perceptions of life and langue in New Zealand, his feelings about study at University of Auckland. The participant actually wrote weekly journals before the research, rather than he was asked to do so. Thus, written samples were provided. 


\section{Data Analysis}

The participant gave his consent to participate in this research and in this article only his data is used. In order to discover the perception of the student, a qualitative approach is being employed. This research is concerned with data management and reduction. By "tidying up" all the data that has been collected, data reduction is a necessary process through coding, summarizing, paraphrasing, focusing. Data is analyzed by following the steps of qualitative data analysis - "coding is analysis", that is, themes are coded and categorized, patterns in the themes are identified and interpretations of these arrangements, during this process, are made.

This analysis employs and adapts the categories from the ones used in Barkhuizen and Feryok's description of teachers' perceptions of an international experience programme. These groupings are broad and inclusive, thus provide a manageable system with which to examine the data.

\section{FINDINGS}

In the interview, the participant was asked what he hoped to achieve through his participation in his postgraduate study (in language teaching). Responses to that question suggest the expectations he had about the programme and his stay in New Zealand generally. The themes he expressed are summarized below in Table 1 .

TABLE I. PARTICIPANT'S PRECONCEPTIONS OF HIS EXPERIENCE

\begin{tabular}{l} 
Themes \\
\hline Improve English proficiency \\
Develop confidence using English \\
Have an international experience \\
Learn about a different lifestyle \\
Become independent \\
Make new friends \\
Learn about New Zealand \\
Learn how to learn in the western university \\
\hline
\end{tabular}

As would be expected with data that included a journal with open-ended topics, a large number of themes were coded. Table 2 shows in random order many of the themes most frequently mentioned by the participant in his journal, a range which displays the diversity of topics chosen for reflection and articulation.

TABLE II. VARIETY OF THEMES REPRESENTED IN JOURNALS

\begin{tabular}{l|l}
\hline \multicolumn{2}{c}{ Themes } \\
\hline Improving English & Challenge \\
Language proficiency & Being with classmates \\
Educational systems & New experiences \\
Assignments & The weather \\
Number of Asians & Making friends \\
Classroom interaction & New Zealand life \\
Lecturers & The population \\
Program effectiveness & \\
\hline
\end{tabular}

As is evident, there is a considerable overlap between the themes in Tables 1 and Table 2. Further analysis of the coded themes revealed four main categories (see Table 3 ) in which the participant articulated his expectation and experience. To present these, I use his words to illustrate the range of similar and sometimes contradictory perceptions. The focus will be on the categories of New Zealand Culture, Language Development, Pedagogical Understanding and
Emotional Intelligence, since they more directly address the personal and academic components of the programme.

TABLE III. MAIN CATEGORIES OF SALIENT THEMES

\begin{tabular}{l|l}
\hline \multicolumn{2}{c}{ Categories } \\
\hline 1. NZ Culture & 4. Emotional Intelligence \\
2. Language De- & 1) Personal Growth \\
velopment & 2) Identity Management \\
3. Pedagogical & 3) Interpersonal Awareness \\
Understanding & 4) Social Relationship \\
\hline
\end{tabular}

\section{A. New Zealand Culture}

Aspects of New Zealand culture, not surprisingly, were frequently mentioned. Lifestyles, food, the educational system, and population are some of the themes included in this category. Generally, the participant were surprised and disappointed by the presence of so many Asians and other non-English speakers in Auckland which, he claimed, prevented him from immersing himself more fully in an English-speaking environment. He regarded it as the main reason of his slow language development.

\section{B. Language Development}

The participant's comments about his language development were evident in themes such as the language learning environment, different linguistic skill areas, and different teaching styles. Comments relating to language development also covered the academic component of the programme. Even though his language development was not as he had expected, he was quite sure that his English was being improved. During the interview, he showed his attitude toward non-English speakers. He thought that being with them may hinder his success in learning English. As a way to gain access to the western / dominant culture and academic success, he explicitly chose to forge friendships with Kiwis or native English speakers rather than Chinese or non-English speakers.

The effectiveness of the classroom environment for language learning led to a positive comment. He said, "as for academic purposes, the language teaching programme provides an opportunity to develop academic skills" and "there are lots of challenges for me". However, he also showed some disappointment that there were not many chances to interact with local students.

\section{Pedagogical Understanding}

Comments on themes related to the category of pedagogical understanding were not implausible. The participant noticed both the academic and study experience components. One comment summaries that he found the western teaching style most valuable. He commented that he learned some English teaching methodologies through the programme.

During the interview, the participant added that the traditional approach to ELT in his country (China) has been a curious combination of the grammar-translation method and audio-lingualism [12], which is characterised by systematic and detailed study of grammar, extensive use of cross-linguistic comparison and translation, memorisation of structural patterns and vocabulary, painstaking effort to form good verbal habits, an emphasis on written language, and a preference for literary classics. This approach has taken root in, and has drawn strong support from, the Chinese culture of learning, hence its popularity among 
Chinese teachers and learners. This is not surprising that the opportunity to have direct experience of a more communicative approach in language learning' gave him the answer why he was still "poor" in language skills even though he had been studying English for many years in China.

Classroom interaction was a particular theme under the category of pedagogical understanding. The participant also related classroom interaction to cultural differences between New Zealand and China. He said that "the students could interrupt the lecturer or even argue the problem".

\section{Emotional Intelligence}

Emotional intelligence describes the ability, capacity, skill, or a self-perceived grand ability to identify, assess, manage and control the emotions of one's self .[5] However, Salovey and Mayer's [19] conception strives to define it with the confines as "the ability to perceive emotion, integrate emotion to facilitate thought, understand emotions and to regulate emotions to promote personal growth", which views emotions as useful sources of information that help one to make sense of and navigate the social environment.

Emotional intelligence embraces and reveals some aspects in the analysis of the participant's perception of expectation and experience, that is, interpersonal awareness, personal growth, identity management and social relationship. Note that social relationship aspect will not be considered to focus since this article examines the aspects about the participant's academic study.

\section{1) Interpersonal Awareness}

Two themes in particular delineate the category of interpersonal awareness: classmates and being with classmates. The former refers to comments that "classmates are international". Being with classmates, however, refers to the frustration the participant felt at being with Chinese and/or native-English speakers for the academic and social components. "Students from the same country tend to talk in their mother language, even in the class. I don't think it's good to improve English" said the participant. On the other hand, he felt embarrassed to be a group with native-English speakers that "they may speak very fast and you cannot discuss with them successfully because of your language proficiency".

The classroom was not the only places where interpersonal awareness was aroused. Even though the participant had very limited social activities out of the class, he did purposefully socialize with native-speakers and he felt that "it's quite easier" to make friends with kiwis. However, he seldom communicated with his classmates or lecturers out of class, which was one of the reasons that he was just adequate in his academic study, especially his assignments.

\section{2) Personal Growth}

The salience of the themes that form the category of personal growth would be a consequence of the programme, but it was nevertheless surprising at how regularly and freely the participant articulated his perceived growth experience. The academic study was definitely the main reason of his personal growth. However, the social activities, in particular, appeared to lead to personal growth. He commented that his experience led him to face challenges in ways that self-confidence increased.

\section{3) Identity Management}

Identity is not as transparent or unproblematic, which is "never complete" and "always in process".[11] The identity is another theme that, for some possible reasons, generated many comments. The participant was a teacher of English in China and had the 'power' of authority in the class before he studies as a postgraduate student in New Zealand. The social context of the speaking situation and the power relations of the interactants impact strongly on the learner's self-perception in his study, and on whether 'those who speak regard those who listen as worthy to listen' and/or vice versa.

The participant's comments, such as "other students had a very high level of spoken English", illustrate the way relations of power impact on speaking and show how "feelings of inadequacy are frequently socially constructed" [16]. He identified himself as underqualified for the postgraduate programme, however, struggled to seek and develop new identities positively. During the interview, he positioned himself strongly as an "ESL speaker". And he said, "I'm quite sure that I'll have improved my language skills at the end of the semester. It is just a step-by-step thing."

\section{DISCUSSION}

Pertaining to the research questions, the learner's articulations reveal that his expectation and experience interrelate in complex, sometimes unexpected, ways (Table 4).[1] Batson, Shaw and Oleson [4] claims that it is clear, however, that, without the perceptions "reflected by positive and negative effect", the experiences would be a neutral gray. The ESL learner develops either a negative or a positive attitude towards English language learning. This attitude, as an outcome of the experience, then, has significant implications for levels of motivation, which gives him a new expectation toward his coming experience.

TABLE IV. REACTIONS ON HIS PERCEPTIONS OF EXPERIENCES

\begin{tabular}{lll}
\hline Experiences & Perceptions a) $\begin{array}{l}\text { Express a feeling: } \\
\text { enjoyment } \\
\text { Make a judgment: } \\
\text { learning English } \\
\text { Make a prediction: } \\
\text { professional teacher }\end{array}$ \\
Expectations & Motivation & Attitude \\
\hline
\end{tabular}

This study aimed to explore the ESL learner's expectation and experience of a postgraduate programme as articulated in the interview and his reflective journal. It became obvious that the interrelationships between these three elements, expectation, experience and utterance/articulation are very complex indeed.

The participant had an expectation before his arrival in New Zealand and had been changing the expectation when he arrived. The expectation is intricately related to his personal motives and goals. Some expectations were realized as experiences but others were not. The experience generates new expectations. Expectations and experiences are therefore reflected by the articulations, which can lead to deeper understandings of those experiences.

As evidenced in this study, when the learner experienced a linguistic and cultural disconnect, the learning environment can become hostile. Drawing on the notion of 
perceptions that signify one's ways of feeling and acting, critical reflection can provide us the opportunity to examine and analyze the participant's perceptions of his experiences. The following considerations are implicated.

First of all, broadly speaking, different learners from different cultures have different learning styles. That means not everyone will adapt to life in the university, where the teaching style is quite different from the one in their home country, as soon as they start their study. It is likely that the students spend most of the time struggling and adjusting themselves in the study in term of cognitive academic language proficiency.

A second implication is then elicited: the importance of letting the students know as much as possible about the programme well before they start. The advice given about the postgraduate study will influence the learner's expectations before he experiences. Thus, the learner will be sure that what is expected from him. Through the expectations guided by the advice, the learner may not hesitate in the experience. Expectation is not always made in ways that could have a negative impact on the learner.

Therefore, smoother communications are needed to find out and ease the pains (Barkhuizen \& Feryok, 2006) which the learner may suffer from unnecessarily. The communications ensure the adjustments could be made, encouraging the learners to motivate themselves from the recommendations. It is very important to remember that the learner already critically evaluate what they do [1]. That means that it is not because the student don't work harder, but they don't know what to do or what is expected from them. Therefore, helpful guidance is very necessary for the students to be successful in the academic study.

Responses from the participant highlighted an overwhelming desire to be accepted by their fellow class students and teaching staff. While there are plenty of calls for more assistance and recognition of their problems, there is also a strong component of self-help strategies in the responses, and a willingness to try new ways once the issues are fully understood. The latter appears to be mostly contingent on language proficiency. Knowing the culture of the institution will help to generate some practical improvements for learners. At the same time, the process needs to go beyond the physical boundaries of the university.

\section{CONCLUSION}

This paper reports on a project aimed at providing a deeper understanding of the contextually relevant issues facing Chinese ESL students in one of New Zealand universities, as part of the plan to provide some implications aimed at improved teaching and learning outcomes for Chinese students in particular, and all international students in the longer term. Some comment on selected strategies for change has also been included. However, to provide some guarantee of quality outcomes and student satisfaction with the delivery of teaching programs, higher education providers should ensure that the different perspectives of these interest groups are factored into the service equation.

The findings in this study have been generated by the case study approach. It would be useful to take a great number of participants to add on to the richness of the current understanding on the current research topic and to yield the amount of data in order to make generalizations. It is my hope that this research paper can serve as a reference for researchers to replicate in the related research projects.
In concluding this study, amidst the useful findings and new ideas that inform the tertiary practitioners working with international students, and researchers, it is my hope that international students reading this study will be stimulated to reflect on their own transition journeys and glean useful information on how to negotiate in a new cultural and learning environment. The findings on the awareness experience and socialisation are directly relevant to inform the adjustments challenges that they may face during their educational sojourning.

\section{REFERENCES}

[1] Barkhuizen, G. (1998). 'Discovering learners' perceptions of ESL classroom teaching/learning activities in a South African context.' TESOL Quarterly, 32(1), 85-108.

[2] Batson, C. D., Shaw, L. L., \& Oleson, K. C. (1992). 'Differentiating affect, mood, and emotion: Toward functionally based conceptual distinctions'. Review of Personality and Social Psychology, 13: 294-326.

[3] Barkhuizen, G., \& Feryok, A. (2006). 'Pre-service teachers' perceptions of a short-term international experience programme.' Asia-Pacific Journal of Teacher Education, 34(1): 115-34.

[4] Benson, D., \& Hughes, J. (1989). 'The academic listening task: A case study.' TESOL Quarterly, 23: 421-45.

[5] Borg, S. (2006). The distinctive characteristics of foreign language teachers. Language Teaching Research, 10(1): 3-31.

[6] Bradberry, T. \& Greaves, J. (2009). Emotional Intelligence 2.0. San Francisco: Publishers Group West.

[7] Ellis, R., \& Barkhuizen, G. (2005). Analysing Learner Language. Oxford: Oxford University Press.

[8] Hall, S. (1990) 'Cultural identity and diaspora'. In J. Rutherfod (Ed.), Identity, community, culture, difference (pp. 222-37). London: Lawrence \& Wishart.

[9] Hu, G., (2002) 'Potential Cultural Resistance to Pedagogical Imports: The Case of Communicative Language Teaching in China'. Language, Culture and Curriculum, 15(2): 93 - 105.

[10] Mezirow, J. (1990). Fostering critical reflection in adulthood. San Francisco, CA: Jossey-Bass.

[11] Salovey, P. \& Grewal, D. (2005) 'The Science of Emotional Intelligence'. Current Directions in Psychological Science, 14: 281-85.

[12] China, Education NZ (n.d.) New Zealand Education Website. Rretrieved on 27 May 2015 from: http://enz.govt.nz/markets-research/china

[13] Robertson, M., Martin L., Jones S. \& Thomas S. (2000) "International Students, Learning Environments and Perceptions: A case study using the Delphi technique" Higher Education Research \& Development, 19:1, 89102 .

[14] Bashir, S. (2007). Trends in international trade in higher education: Implications and options for developing countries. Washington, DC: The World Bank. Retrieved on 30 May 2015.

[15] Mayhew, M. J., Vanderlinden, K., \& Kim, E. K. (2010). “A multi-level assessment of the impact of orientation programs on student learning." Research in Higher Education, 51(4), 320-345.

[16] Kim, Y.Y. (1995). “Cross-cultural adaptation.” In R.L. Wiseman (Ed.), Intercultural communication theory (pp.171-193).Thousand Oaks, CA: Sage.

[17] Peirce, B.N. (1995) 'Social identity, investment and language learning'. TESOL Quarterly, 29: 9-31.

[18] Mezirow, J. (1990). Fostering critical reflection in adulthood. San Francisco, CA: Jossey-Bass.

[19] Miles, M. B., \& Huberman, A.M. (1994) Qualitative Data Analysis (2 $^{\text {nd }}$ ed.). Thousand Oaks, CA: Sage Publications. 